Original Research

\title{
Workplace Ostracism and Knowledge Hiding: The Mediating Role of Job Tension (Case Study of Nurses of Public Hospitals Employee's in Lorestan)
}

\author{
Reza Sepahvand ${ }^{1}$ (iD), Masoome Momeni Mofrad ${ }^{2}$ iD
}

1. Professor, Department of Management, Faculty of Management and Economics, Lorestan University, Khorramabad, Iran

2. PhD Student in Human Resource Management, Department of Management, Faculty of Management and Economics, Lorestan University, Khorramabad, Iran

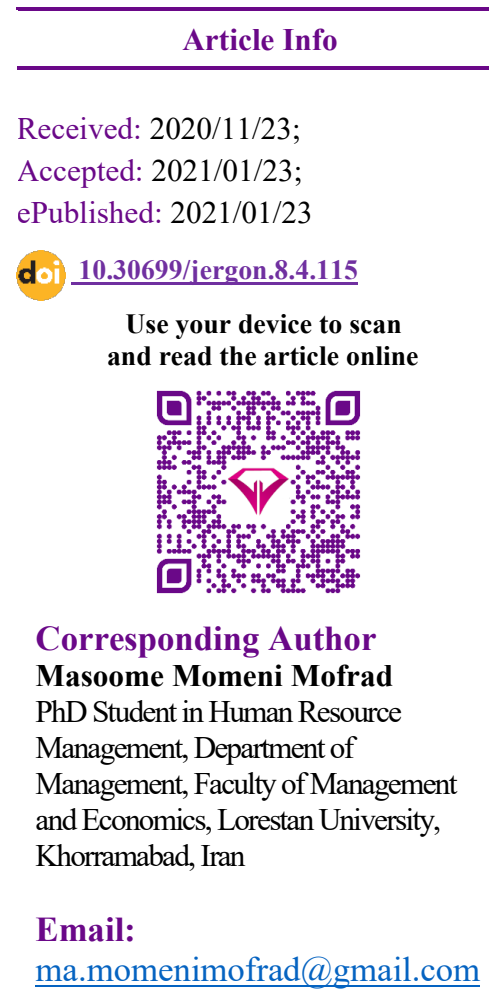

\begin{abstract}
Background and Objectives: Improving and developing service delivery requires the free flow of information and knowledge. Therefore, addressing this factor and examining the role of its determinants can lead to the reputation of the organization in providing services. One of the most important factors is the dismissal of employees in the environment, which leads to a lot of job tension. Therefore, the purpose of this study was to investigate the effect of exclusion in the workplace on knowledge concealment with respect to the mediating role of job tension.
\end{abstract}

Methods: This study is based on the applied purpose and from the perspective of how to collect data in the field of descriptive survey studies. The statistical population of this study consists of all staff of public hospitals in Lorestan province. Using stratified-random sampling method, 124 people were selected as the research sample. The data required in this study were collected using the Liu et al. (2016) Workplace Rejection Questionnaire, the O'Reilly et al. (2014) Knowledge Concealment Questionnaire, and the Peng Job Tension Questionnaire (2013) based on 5 options Likert. The data collected in this study were analyzed by structural equation modeling using Smart-pls software.

Results: The results of this study showed that rejection in the workplace can lead to the spread of knowledge concealment behaviors. Also, rejection through increased job stress can lead to the development of knowledge concealment.

Conclusion: According to the results of this study, managers of service organizations should develop strategies to improve the level of mutual acceptance of people in the workplace and prevent rejection of individuals to reduce knowledge concealment behaviors.

Keywords: Workplace ostracism; Knowledge hiding; Job tension

\footnotetext{
Copyright (C) 2021, This is an original open-access article distributed under the terms of the Creative Commons Attribution-noncommercial 4.0 International License which permits copy and redistribute of the material just in noncommercial usages with proper citation.
}

\section{How to Cite This Article:}

Sepahvand R, Momeni Mofrad M. Workplace Ostracism and Knowledge Hiding: The Mediating Role of Job Tension (Case Study of Nurses of Public Hospitals Employee's in Lorestan) . Iran J Ergon. 2020; 8 (4) :115-128 


\section{Extended Abstract}

\section{Introduction}

Improving and developing service delivery requires the free flow of information and knowledge. Therefore, addressing this factor and examining the role of its determinants can lead to the reputation of the organization in providing services. One of the most important factors is the dismissal of employees in the environment, which leads to a lot of job tension. Therefore, the purpose of this study was to investigate the effect of rejection in the workplace on knowledge concealment with respect to the mediating role of job tension.

\section{Methods}

This study is based on the applied purpose and from the perspective of how to collect data in the field of descriptive survey studies. The statistical population of this study consists of all staff of public hospitals in Lorestan province. Using stratified-random sampling method, 124 people were selected as the research sample. The data required in this study were collected using the Liu et al. (2016) Workplace Rejection Questionnaire, the O'Reilly et al. (2014) Knowledge Concealment Questionnaire, and the Peng Job Tension Questionnaire (2013) based on 5 options Likert. The data collected in this study were analyzed using structural equation modeling by Smart-Pls software.

\section{Results}

The results of this study showed that rejection in the workplace can lead to the spread of knowledge concealment behaviors. Also, rejection through increased job tension can lead to the development of knowledge concealment.

Table 1. Demographic characteristics

\begin{tabular}{|c|c|c|}
\hline Variable & Period & Frequency \\
\hline \multirow{4}{*}{ Age } & Less than 30 years & 28 \\
\hline & Between 30 and 40 years & 49 \\
\hline & Between 41 and 50 years & 34 \\
\hline & More than 50 years & 13 \\
\hline \multirow{2}{*}{ Gender } & Male & 79 \\
\hline & Female & 45 \\
\hline \multirow{3}{*}{ Work history } & Less than 10 years & 36 \\
\hline & Between 10 and 20 years & 53 \\
\hline & More than 20 years & 35 \\
\hline
\end{tabular}

Table 2. Model fit indices

\begin{tabular}{|ccccccccc} 
Variable & M & SD & $\begin{array}{c}\text { Convergent } \\
\text { validity }\end{array}$ & $\begin{array}{c}\text { Composite } \\
\text { reliability }\end{array}$ & $\mathbf{R}^{2}$ & $\mathbf{F}^{2}$ & $\mathbf{Q}^{2}$ & $\begin{array}{c}\text { Cronbach's } \\
\text { alpha }\end{array}$ \\
\hline $\begin{array}{c}\text { Knowledge } \\
\text { concealment }\end{array}$ & 3.486 & 0.737 & 0.821 & 0.889 & 0.734 & 0.695 & 585 & 0.890 \\
$\begin{array}{c}\text { Workplace } \\
\text { rejection }\end{array}$ & 3.589 & 783 & 0.565 & 0.873 & - & - & - & 0.834 \\
\hline \begin{tabular}{c} 
Job tension \\
\hline
\end{tabular} & 3.474 & 854 & 0.536 & 0.932 & 0.638 & 0.497 & 0.317 & 0.856 \\
\hline
\end{tabular}




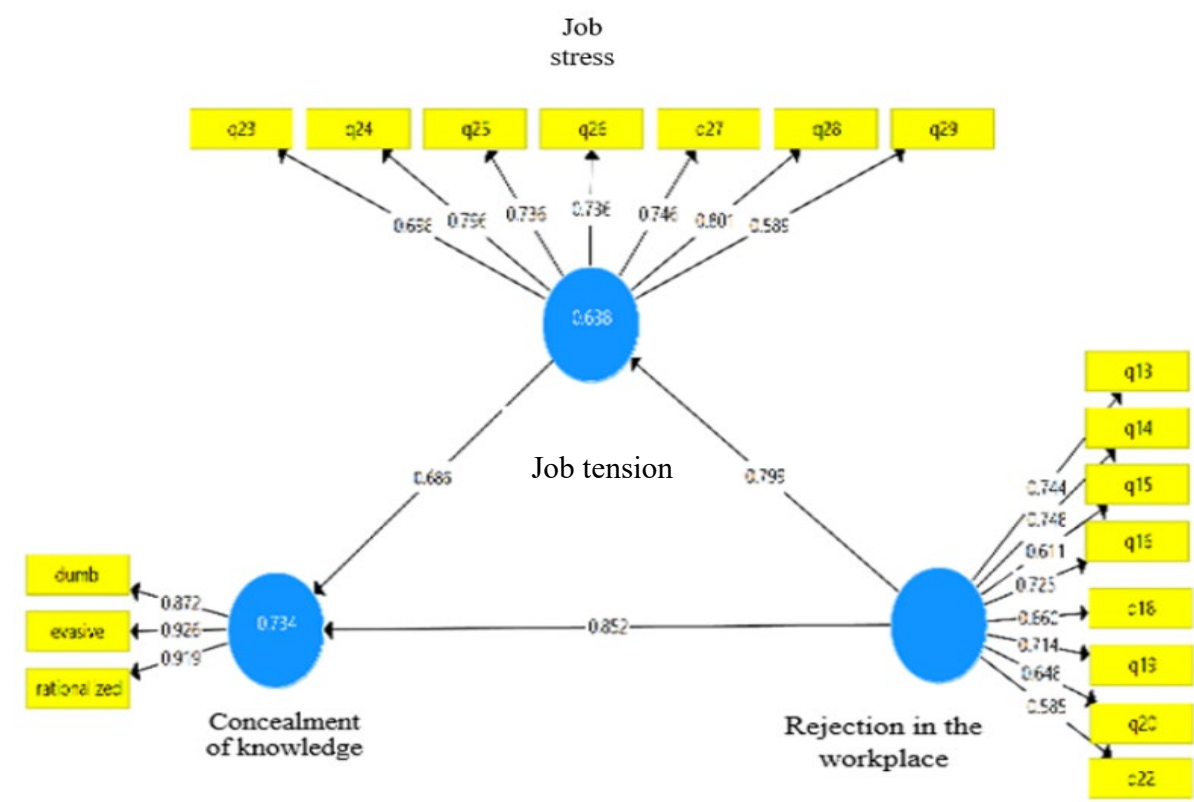

Figure 1. Model of research path coefficients

Table 3. Divergent validity

\begin{tabular}{|c|c|c|c|}
\hline Variable & $\begin{array}{l}\text { Knowledge } \\
\text { concealment }\end{array}$ & Workplace rejection & Job tension \\
\hline Knowledge concealment & 0.906 & & \\
\hline Workplace rejection & 0.807 & 0.751 & \\
\hline Job tension & 0.634 & 0.688 & 0.732 \\
\hline
\end{tabular}

Table 4. Goodness index Fit

\begin{tabular}{|c|c|c|c|}
\hline Variable & $\begin{array}{c}\text { The coefficient of } \\
\text { determination }\end{array}$ & Shared index & Goodness of fit \\
\hline Knowledge concealment & 0.734 & 0.311 & \multirow{2}{*}{0.193} \\
\hline Job tension & 0.638 & 0.254 & \\
\hline
\end{tabular}

$$
\mathrm{GOF}=\sqrt{\overline{\text { Communality }} \times \overline{R^{2}}}=0.193
$$

The amount of goodness of fit was 0.193, which provides an average and acceptable amount. This result shows that therapeutic activities have a complex structure and various factors with different effects are involved in the formation of its various aspects.

Table 5. Sobel test

\begin{tabular}{|cccccc}
\hline Relation & Mediator & Side track & $\begin{array}{c}\text { Path } \\
\text { coefficient }\end{array}$ & $\begin{array}{c}\text { SD } \\
\text { Sobel } \\
\text { test }\end{array}$ \\
\hline $\begin{array}{c}\text { The effect of workplace rejection } \\
\text { on knowledge concealment }\end{array}$ & $\begin{array}{c}\text { Job } \\
\text { tension }\end{array}$ & $\begin{array}{c}\text { The effect of rejection in the } \\
\text { workplace on job tension }\end{array}$ & $\begin{array}{c}\text { The effect of job tension on } \\
\text { knowledge concealment }\end{array}$ & 0.799 & 0.030 \\
\hline
\end{tabular}




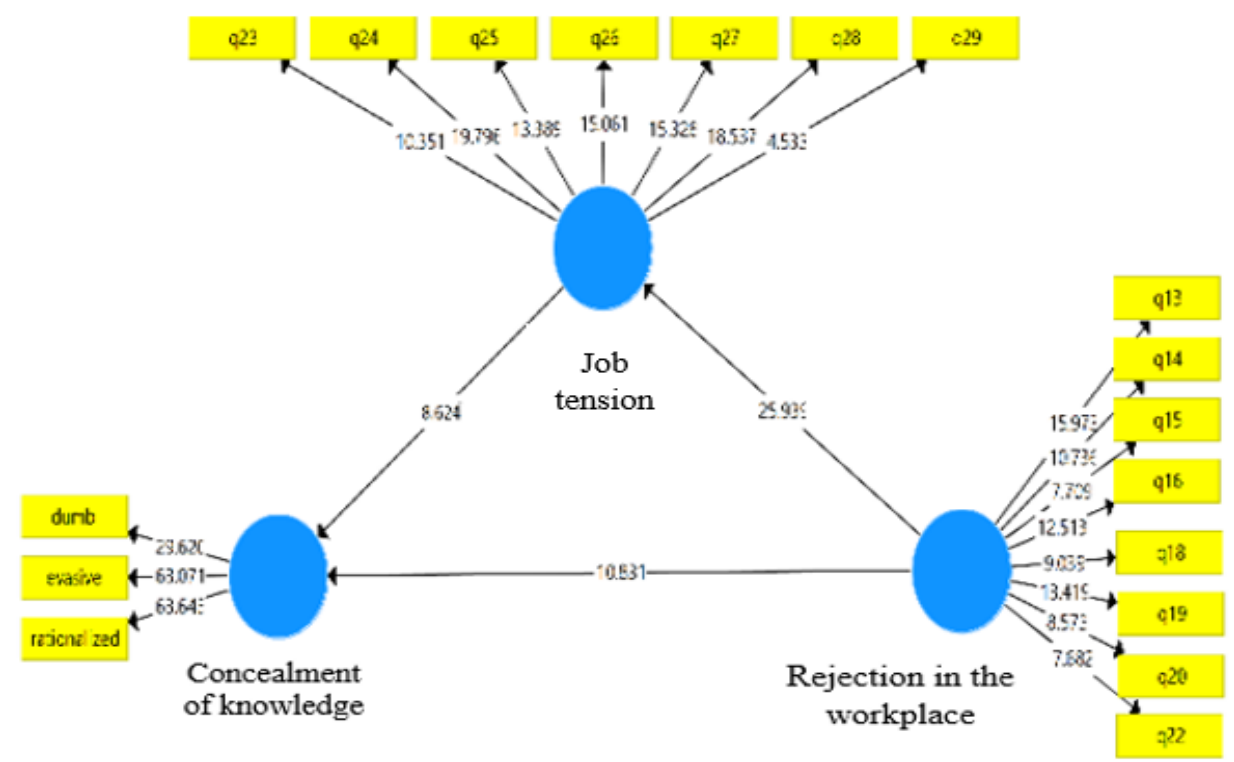

Figure 2. Statistical t-test of research hypotheses

Table 6. Hypothesis test results

\begin{tabular}{|ccccc|}
\hline Connection & $\begin{array}{c}\text { Path } \\
\text { coefficient }\end{array}$ & T-test & Result \\
\hline Rejection in the workplace affects job tension. & 0.799 & 25.935 & Approved \\
\hline Rejection in the workplace affects the concealment of knowledge. & 0.852 & 10.831 & Approved \\
\hline Job tension affects the concealment of knowledge. & 0.686 & 8.624 & Approved \\
\hline Rejection in the workplace through job tension affects the concealment & 0.548 & 5.902 & Approved \\
\hline
\end{tabular}

\section{Discussion}

The results of this study showed that rejection in the workplace has a positive effect on knowledge concealment; in such a way that increasing the rejection of employees in the workplace leads to the development of knowledge concealment behaviors. This type of abuse in the workplace negatively affects individual and organizational performance indexes. Rejection by co-workers causes the emotional connection between members of the organization to diminish or disappear altogether. Lack of empathy among people also lowers trust; therefore, instead of forming a team spirit to achieve the goals of the organization, there is a kind of non-constructive competition and conflict among the members of the organization. As a result, employees try to keep their specific and general information and knowledge secret from others and try to ensure that no one has access to this knowledge. This leads to behaviors that will lead to the concealment of knowledge. These behaviors can take many forms, such as irrelevant and short answers to coworkers or escaping coworker questions. All of these behaviors have negative aspects and irreparable costs for the individual and the organization. As a result, rejection in the workplace has been able to increase knowledge concealment behaviors. The findings of this study in this section are consistent with the results of the study of Lyu et al. (2016).

In addition to examining the direct relationship between workplace rejection and knowledge concealment, the present study evaluated the mediating role of job tension in the relationship between rejection and concealment behaviors. These results indicate that job tension as a psychological tension plays an important role in increasing knowledge concealment behaviors. Job 
tension means the perception of the inability to control bad situations in the workplace. Behaviors such as the negligence of co-workers and the unusual behavior of other members of the organization cause people to be in a difficult emotional state, as if they think they cannot do their job or cannot do it properly and on time. This perception, which arises from the dysfunctional behaviors of co-workers in individuals, leads to mental disorders in the workplace, the direct result of which is the creation of a specific work area with a defined boundary. This domain does not allow individuals to establish and share information; therefore, people try to make their information and knowledge available to others as much as possible. The result of these activities is an increase in knowledge concealment behaviors. Overall, it can be said that the rejection of employees in the workplace by colleagues and managers causes people to suffer from numerous psychological and interpersonal conflicts. As a result, tensions between people increase, and thus people form unfavorable connections and exchanges with their colleagues and try to conceal their knowledge from others. Thus, knowledge concealment behaviors increase among employees and rejection in the workplace through job tension leads to knowledge concealment. The main difference between the results of this study and the findings of similar previous researches was first in the field and the emphasis was on medical services. Also, data analysis showed that the study of the two factors of rejection in the workplace and job tension, explains only part of the changes in knowledge concealment that is not long-awaited due to the nature of therapeutic activity.

\section{Conclusion}

According to the results of this study, managers of service organizations should develop strategies to improve the level of mutual acceptance of people in the workplace and prevent rejection of individuals to reduce knowledge concealment behaviors.

\section{Acknowledgement}

The authors of this article would like to thank all the staff of public hospitals in Lorestan Province who have participated in this study.

\section{Conflict of Interest}

The authors declared no conflict of interest. 
طردشدكى در محيط كار و ينهانسازى دانش با نقش ميانجى تنش شغلى

(مورد مطالعه كاركنان بيمارستان هاى دولتى استان لرستان)

(iD) رضا سيهوند' (D) معصومه مومنى مفرد)

l . استاد، گروه مديريت، دانشكدة مديريت و اقتصاد، دانشكاه لرستان، خرمآباد، ايران

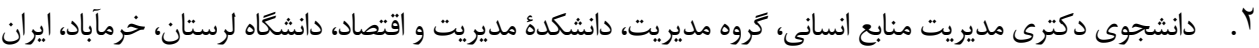

\begin{tabular}{|c|c|}
\hline خلاصه & اطلاعات مقاله \\
\hline 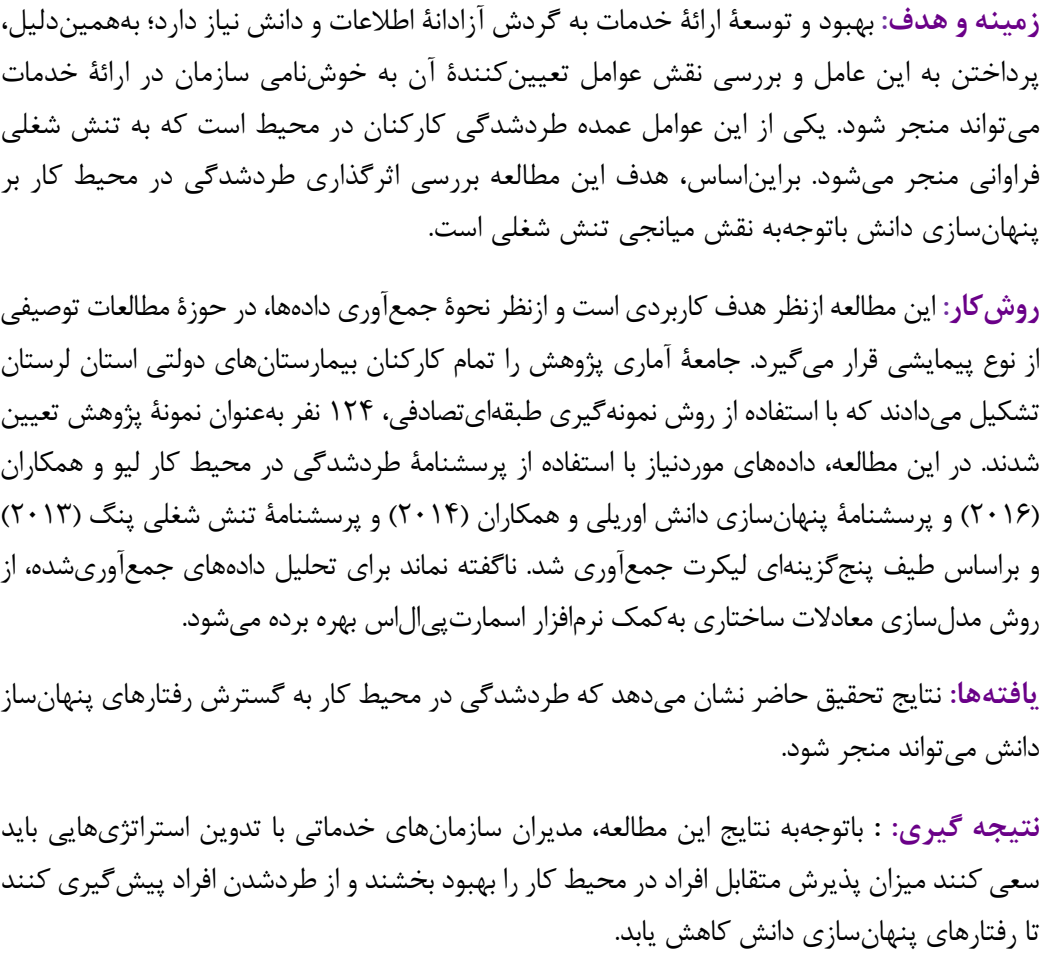 & 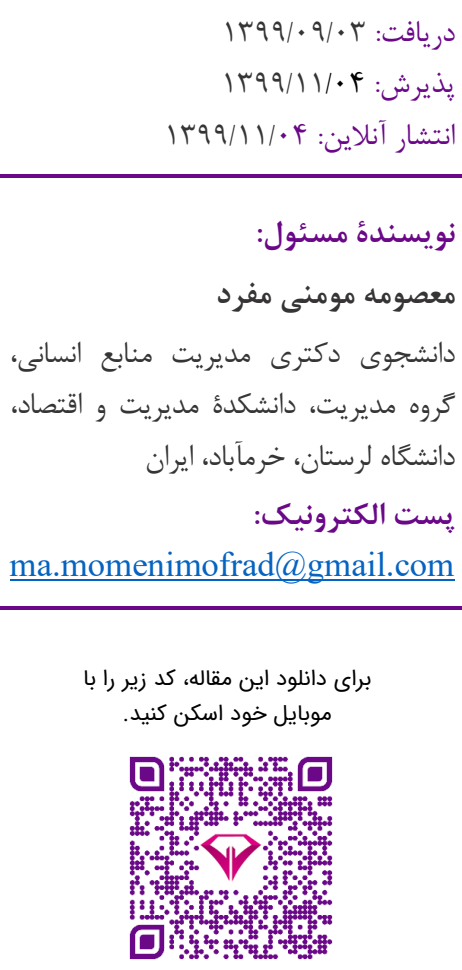 \\
\hline كليدوازهها: طردشدگى در محيط كار، ينهانسازى دانش، تنش ش & \\
\hline
\end{tabular}

مقدمه

ينهانسازى دانش به تلاش عمدى شخص براى جلوگيرى يا

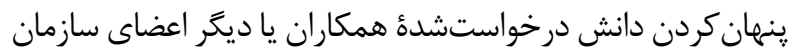

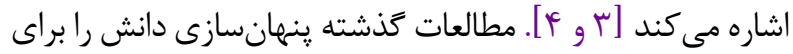

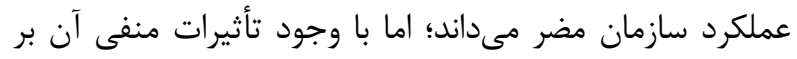

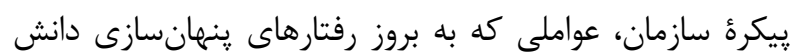
بلويزه در سازمانهاى خدماتى منجر مىشوند، تاكنون بهطور

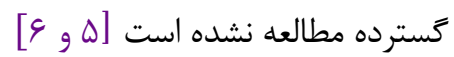

در عصر حاضر، تسهيمم دانش بهعنوان يكى از كامهاى حياتى

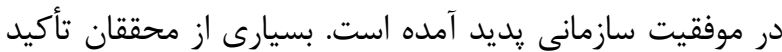
مى كنند كه جنين يديدهاى براى سازمانهاى خدماتى بهمنظور

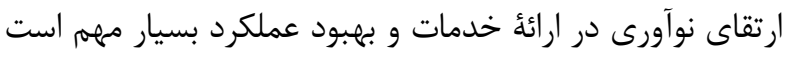

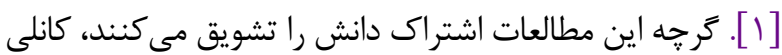
و همكاران خاطرنشان كردند كاركنان تصميم مى گيرند كه اجازه دسترسى ديكران را به دانش موجود نزد خود ندهند. اين رفتار

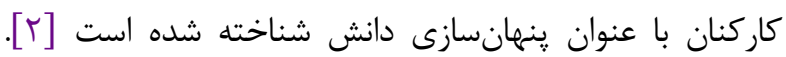


طردشدكى در محل كار و رفتارهاى توليدى كاركنان است.

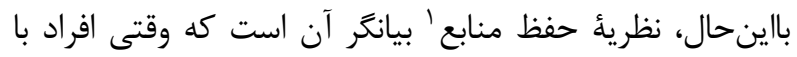

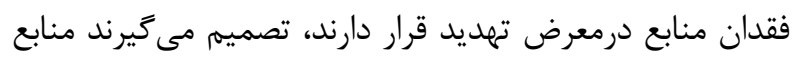

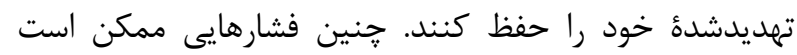

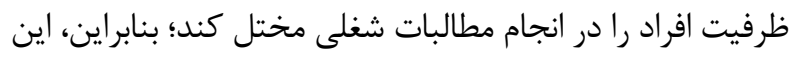
مطالعه به كسترش ادبيات ازطريق بررسى تجربى در زمينه تأثير

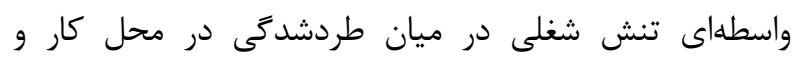

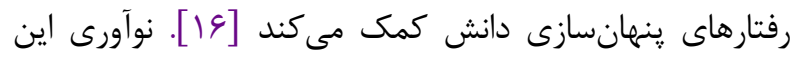

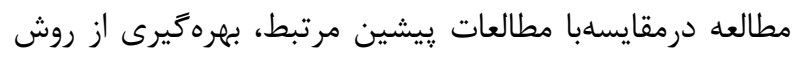

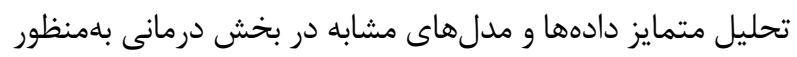

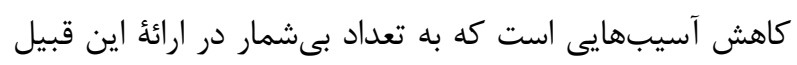

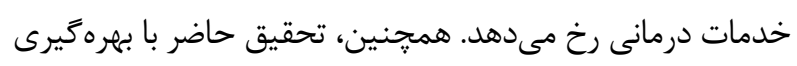

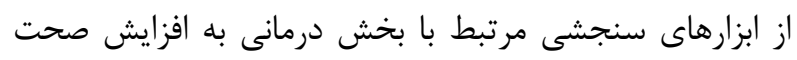
نتايج حاصلشده مى تواند منجر شود.

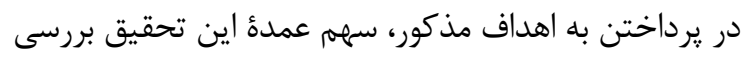

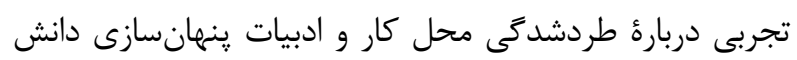

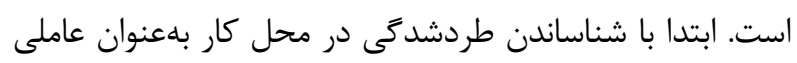

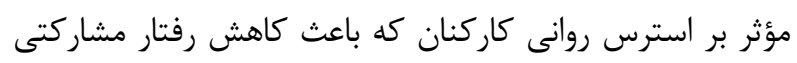

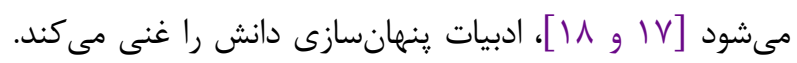
سيس، متناسب با نقش تعيين كننده عوامل زمينهاى شغل، نقش

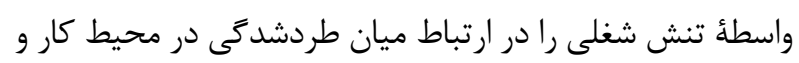

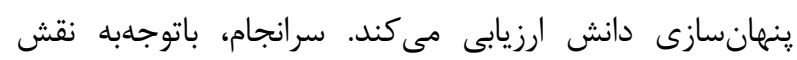

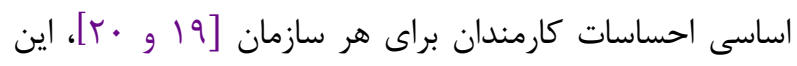

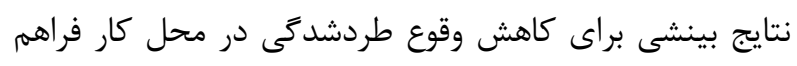

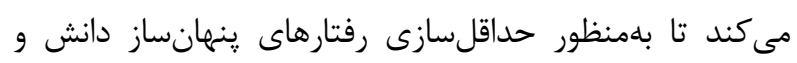

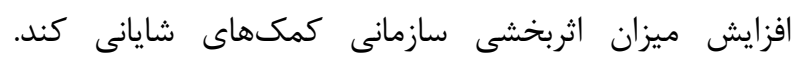

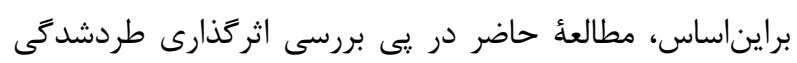

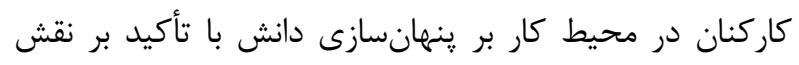
ميانجى تنش شغلى است.

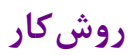

ازنظر هدف، مطالعٔ حاضر كاربردى است؛ جراكه نتايجش رون

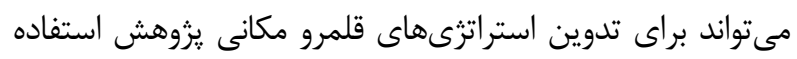

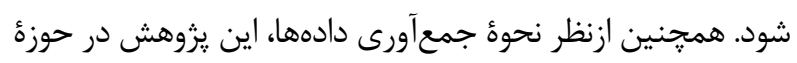

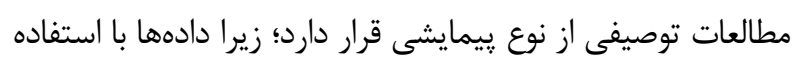

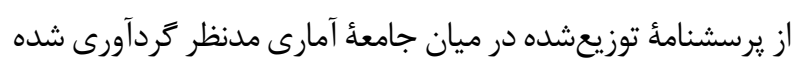

تحقيقات اخير زائو و همكاران [V] نشان مى دهد ينهان كردن

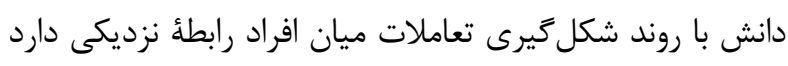

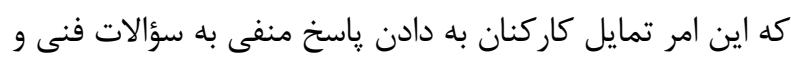

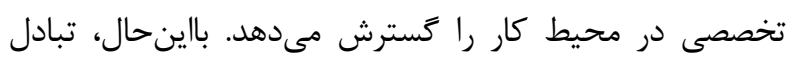

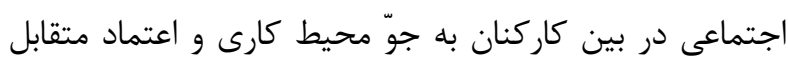

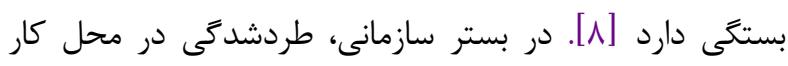

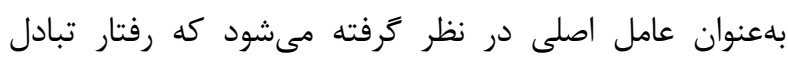

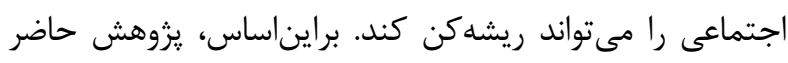

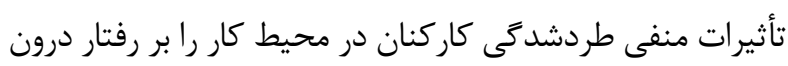

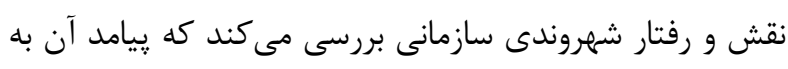

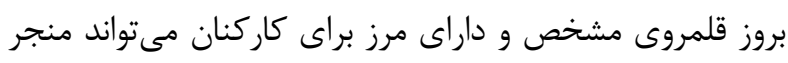

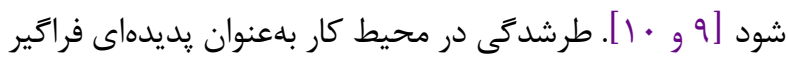

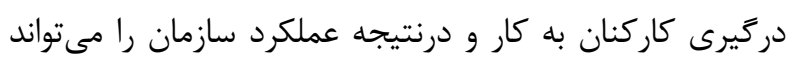

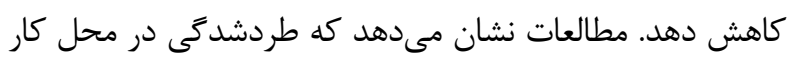

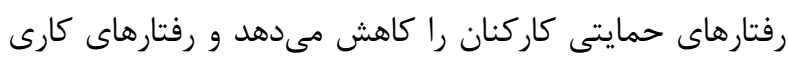

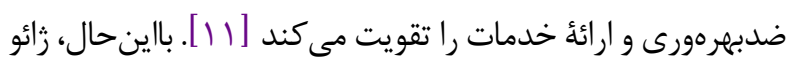

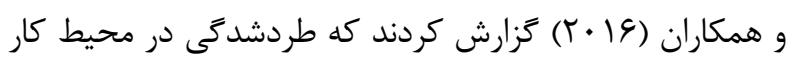

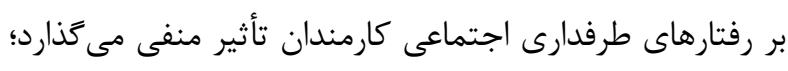

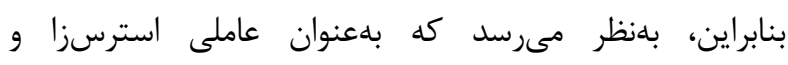

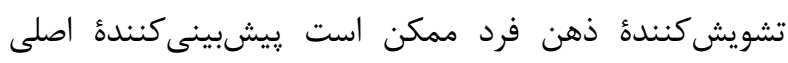
ينهان كردن دانش باشد.

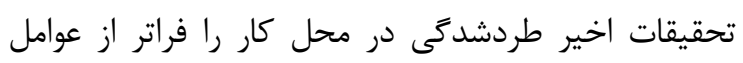

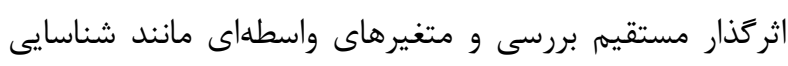

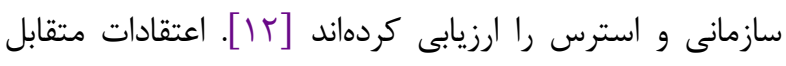

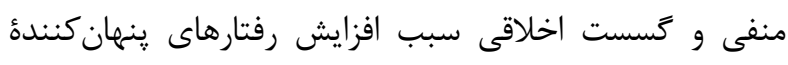

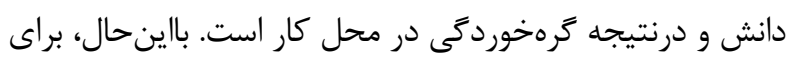

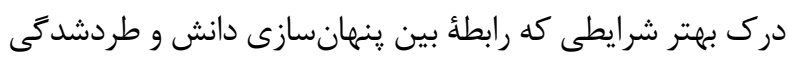

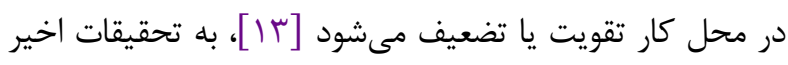

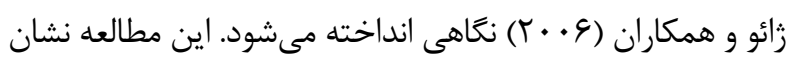

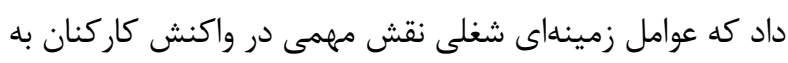

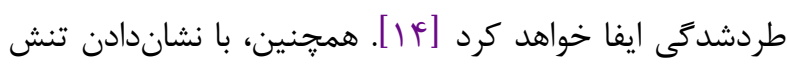

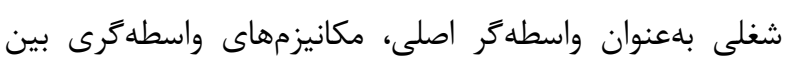

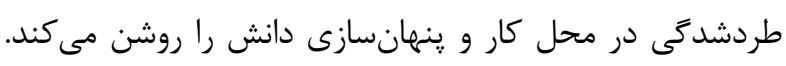

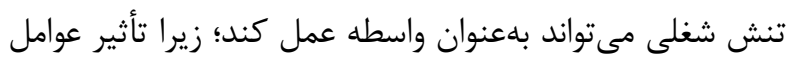

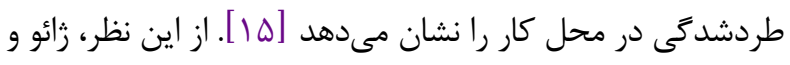

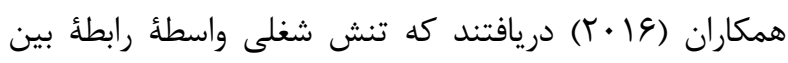

\section{COR}


است. پس از توزيع يرسشنامه و جمعآورى دادهها، فرضيههاى اين

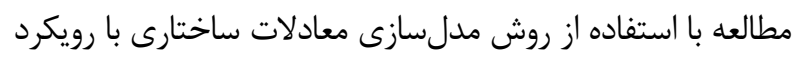

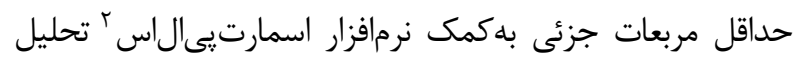

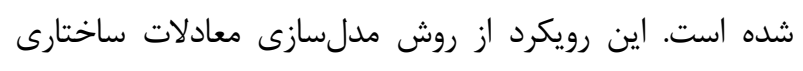

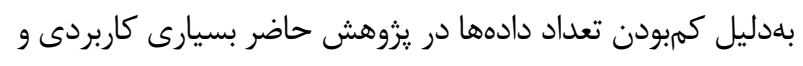

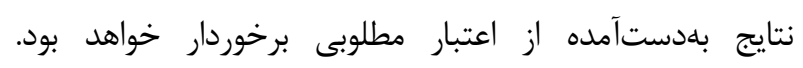

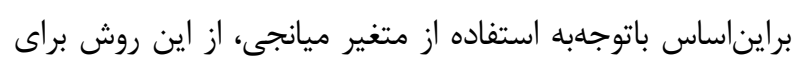

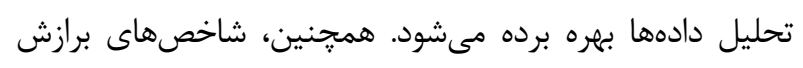

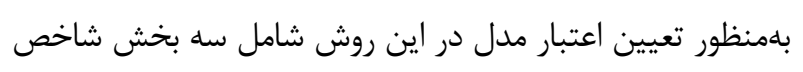

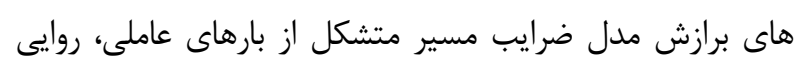

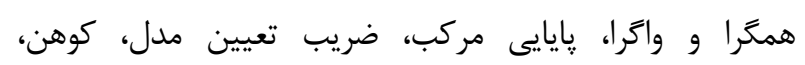

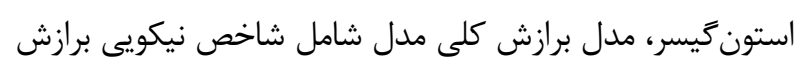

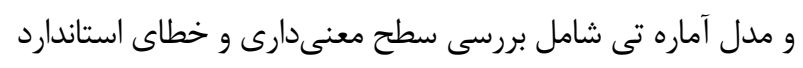
و ميزان آمارةٔ تى است كه درادامه بررسى مى شعىند.

\section{يافته ها}

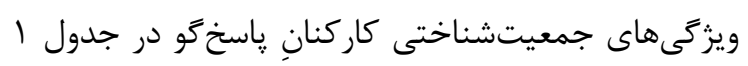

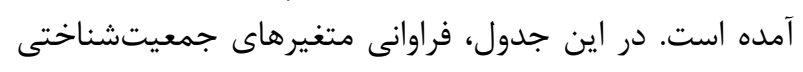

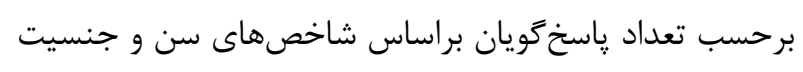

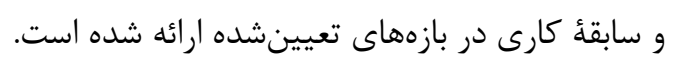

است. ازنظر نحؤ تحليل دادهها نيز، تحقيق حاضر در حوزءٔ مطالعات

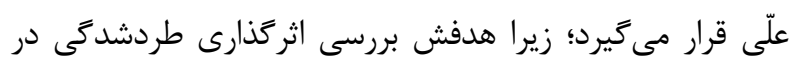

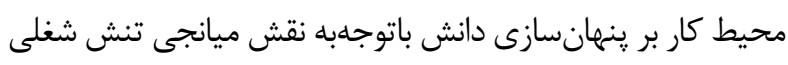

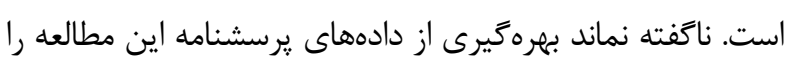

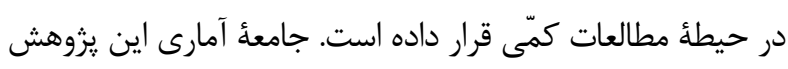

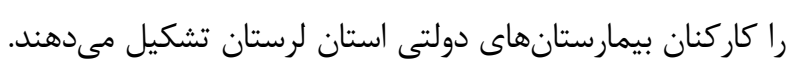

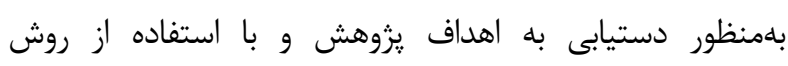
نمونه گيرى طبقایى تصادفى و به كمك فرمول كوكران، حجم نمونه

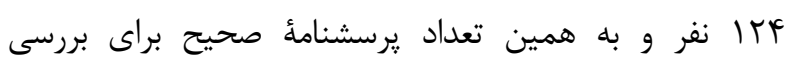
فرضيههاى يزوهش در نظر ترفته شده است.

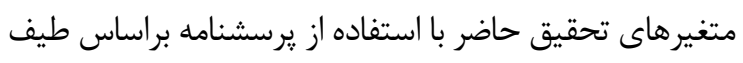

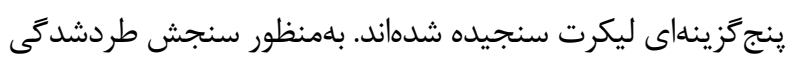

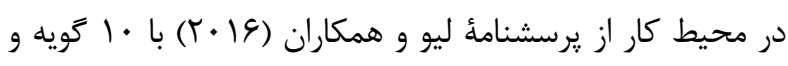

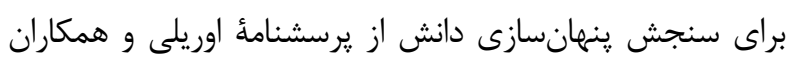

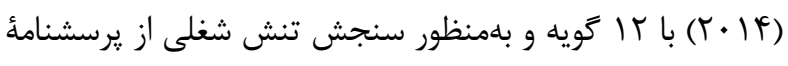

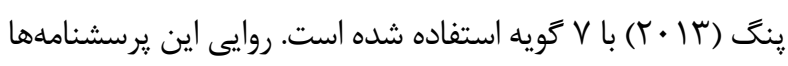

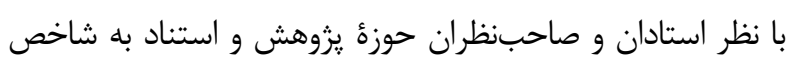

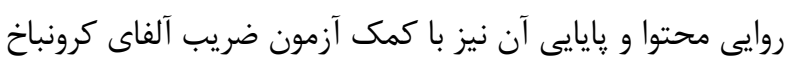

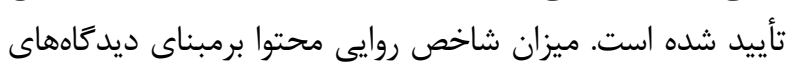

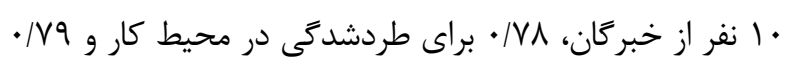

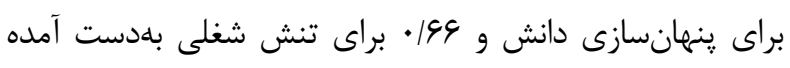

\begin{tabular}{|c|c|c|}
\hline فراوانى & بازه & متغير \\
\hline r^ & كمتر از • ب سال & \multirow{4}{*}{ سن } \\
\hline $4 q$ & بين •r تا • r سال & \\
\hline re & بين أf تا •ه سال & \\
\hline M & بيشتر از •له سال & \\
\hline vq & مرد & \multirow{2}{*}{ جنسيت } \\
\hline is & زن & \\
\hline re & كمتر • ا سال & \multirow{3}{*}{ سابقة كارى } \\
\hline$\Delta r$ & بين •ا تا • ب سال & \\
\hline rd & بيشتر از • r سال & \\
\hline
\end{tabular}

\section{Smart-Pls}




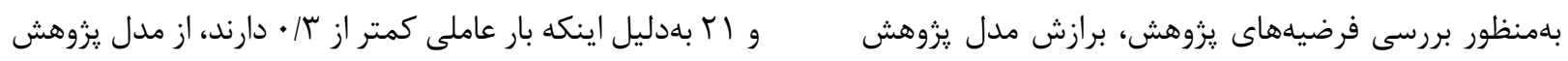

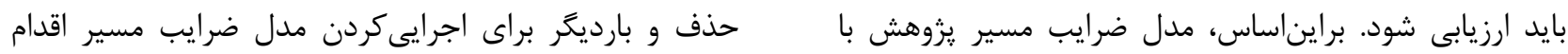

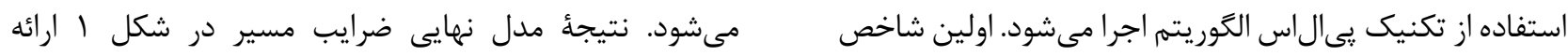

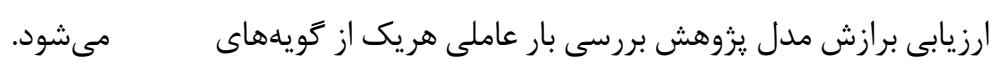

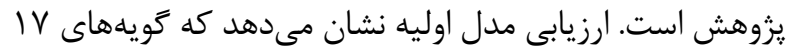

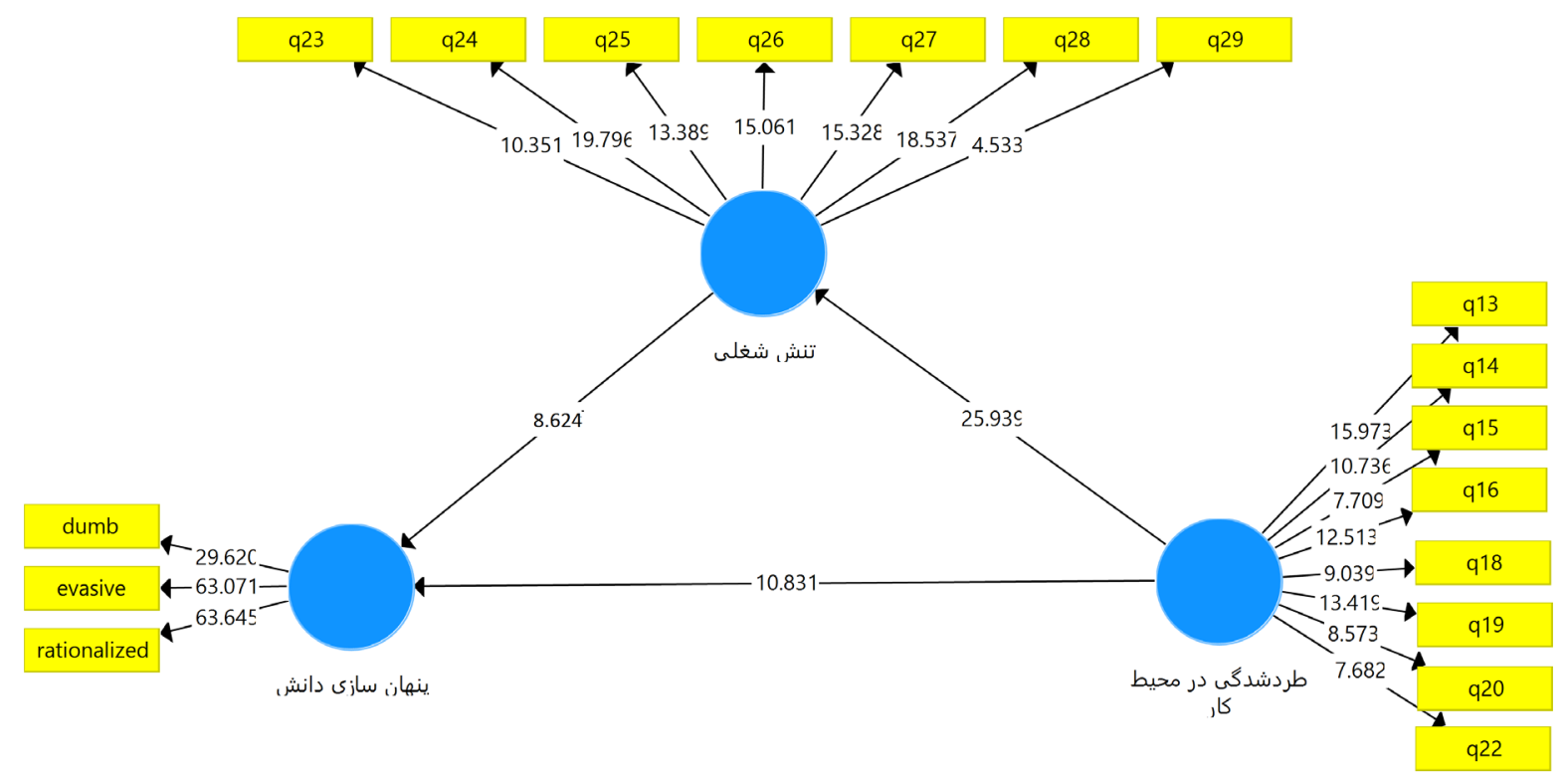

شكل 1. مدل ضرايب مسير يثوهش

برازش مدل يزوهش با استفاده از شاخصهاى روايى همكرا استونَيسر و نيكويى برازش انجام شده است. نتيجأ بررسى

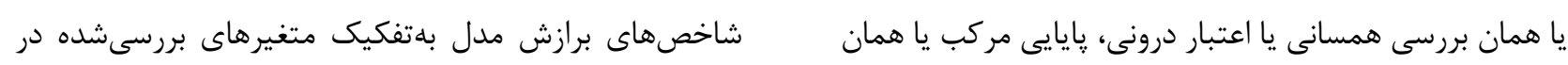

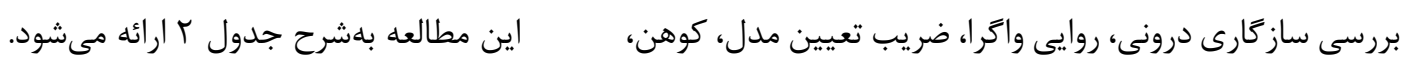

جدول r. شاخص هاى برازش مدل

\begin{tabular}{|c|c|c|c|c|c|c|c|c|}
\hline كرونباخ & $\mathrm{Q}^{2}$ & $\mathrm{~F}^{2}$ & $\mathrm{R}^{2}$ & هركب & همَّرا & انحرافِمعيار & ميانَين & متغير \\
\hline . 119. & $\Delta \wedge \Delta$ & .1990 & . IVMF & $\cdot / 1 \wedge 9$ & - $|A T|$ & $\cdot / V r V$ & T/Fへ૬ & هنهانسازى دانش \\
\hline - IAKF & - & - & - & $\cdot / \Lambda V T$ & $\cdot 1 \Delta \Leftrightarrow \Delta$ & ·IVAr & $r / \Delta \wedge q$ & طردشيط كار در \\
\hline$\cdot / \Lambda \Delta \varphi$ & • MIV &.$/ 4 q V$ & $\cdot \mid g r \wedge$ & . & - IOHE & $\cdot \mid \wedge \Delta F$ & $r / F V F$ & تنش شغلى \\
\hline
\end{tabular}

متغيرهاى ينهان انعكاسى موجود در مدل بيشتر باشد، روايى

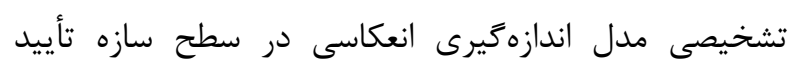
مىشود. نتيجهُ تحليل روايى واگرا در جدول س ارائه شده است.
براى سنجش روايى تشخيصى در سطح سازه (متغيرهاى ينهان)، از مقادير AVE حاصلشده بايد جذر گرفت. جنانجه جذر AVE براى هر متغير ينهان از همبستخى آن متغير با ساير 
جدول r. روايى واترا

\begin{tabular}{|c|c|c|c|}
\hline تنش شغلى & طردشدىى در محيط كار & ينهانسازى دانش & متغير \\
\hline & & $\cdot 19 \cdot 9$ & ينهان سازى دانش \\
\hline & $\cdot|V \Delta|$ & $\cdot / \Lambda \cdot V$ & طردشدكى در محيط كار \\
\hline . IVTr & $\cdot \mid 9 \wedge \Lambda$ &. $\mid g r F$ & تنش شغلى \\
\hline
\end{tabular}

نشاندهنده اين است كه متغيرهاى مشاهدهيذير ماتريس

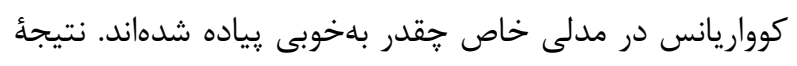
بdدستآمده در جدول \& أرائه شده است.
در يزوهش حاضر، برازش كلى مدل با بهرهزيرى از شاخص

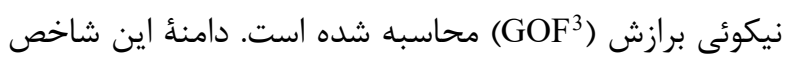

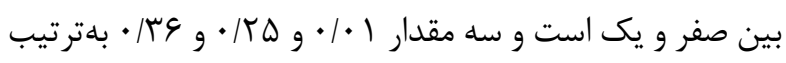
مقادير ضعيف و متوسط و قوى را نشان مىدهد. شاخص (GOF)

جدول F. - ماخص نيكويىبرازش

\begin{tabular}{|c|c|c|c|}
\hline نيكويىبرازش & شاخص اشتراكى & ضريب تعيين & متغير \\
\hline \multirow{2}{*}{. } & $\cdot / \pi 11$ & - /VMF & ينهانسازى دانش \\
\hline & $\cdot / T \Delta F$ &. $\mid 9 \mu \Lambda$ & تنش شغلى \\
\hline
\end{tabular}

\section{آزمون سوبل}

بdمنظور بررسى معنادارى اثر متغيرهاى ميانجى از آزمون

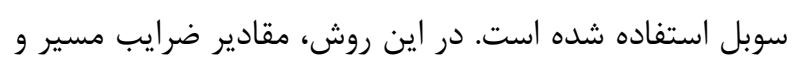

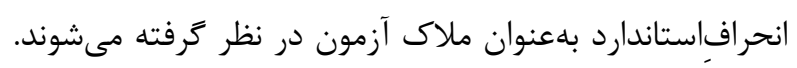
نتيجة حاصلشده را در جدول ه مشاهده مى كنيد. باتوجهبه

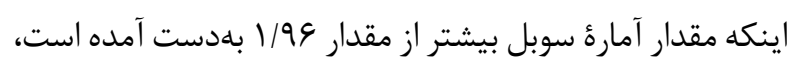

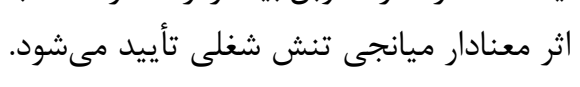

$$
\mathrm{GOF}=\sqrt{\overline{\text { Communality }} \times \overline{R^{2}}}=0.193
$$
ميزان نيكويىبرازش سو || • بهدست آمده است كه مقدار متوسط و مقبولى ارائه مى كند. اين نتيجه نشان مى مدهد كه

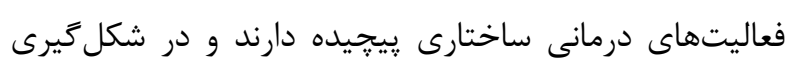

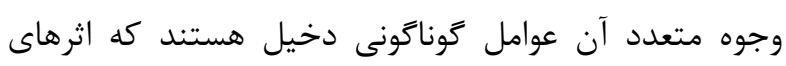
متفاوتى برجاى مى حذارند.

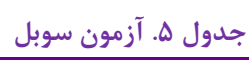

\begin{tabular}{|c|c|c|c|c|c|}
\hline سوبل & انحراف|ستاندارد & ضريب & مسير فرعى & ميانجى & رابطه \\
\hline \multirow{2}{*}{$\Lambda / T \Delta \Delta$} & $\cdot / \cdot r$. & •/V११ & تأثير طردشدگى در محيط كار بر & \multirow{2}{*}{ تنش شغلى } & \multirow{2}{*}{ تأثير طردشدكى در محيط كار بر } \\
\hline & $\cdot 1 \cdot \vee 9$ & $.19 \wedge 9$ & تأثير تنش شغلى بر ينهانسازى & & \\
\hline
\end{tabular}

كمتر از 1/99- حاصل شود، آن رابطه تأييد مىشود؛ وكرنه

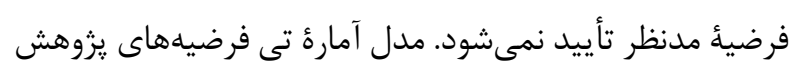
در شكل r آمده است. نتيجه آزمون فرضيههاى يزوهش در أمدات جدول عارائه شده است.

\author{
آزمون فرضيه \\ آزمون فرضيههاى يزوهش با استفاده از معنادارى ضرايب \\ مسير و جهت علامت ضريب بتاى مدل بررسى شده است. آر

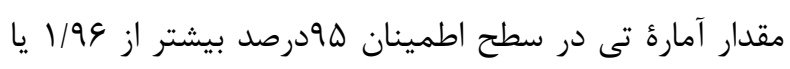




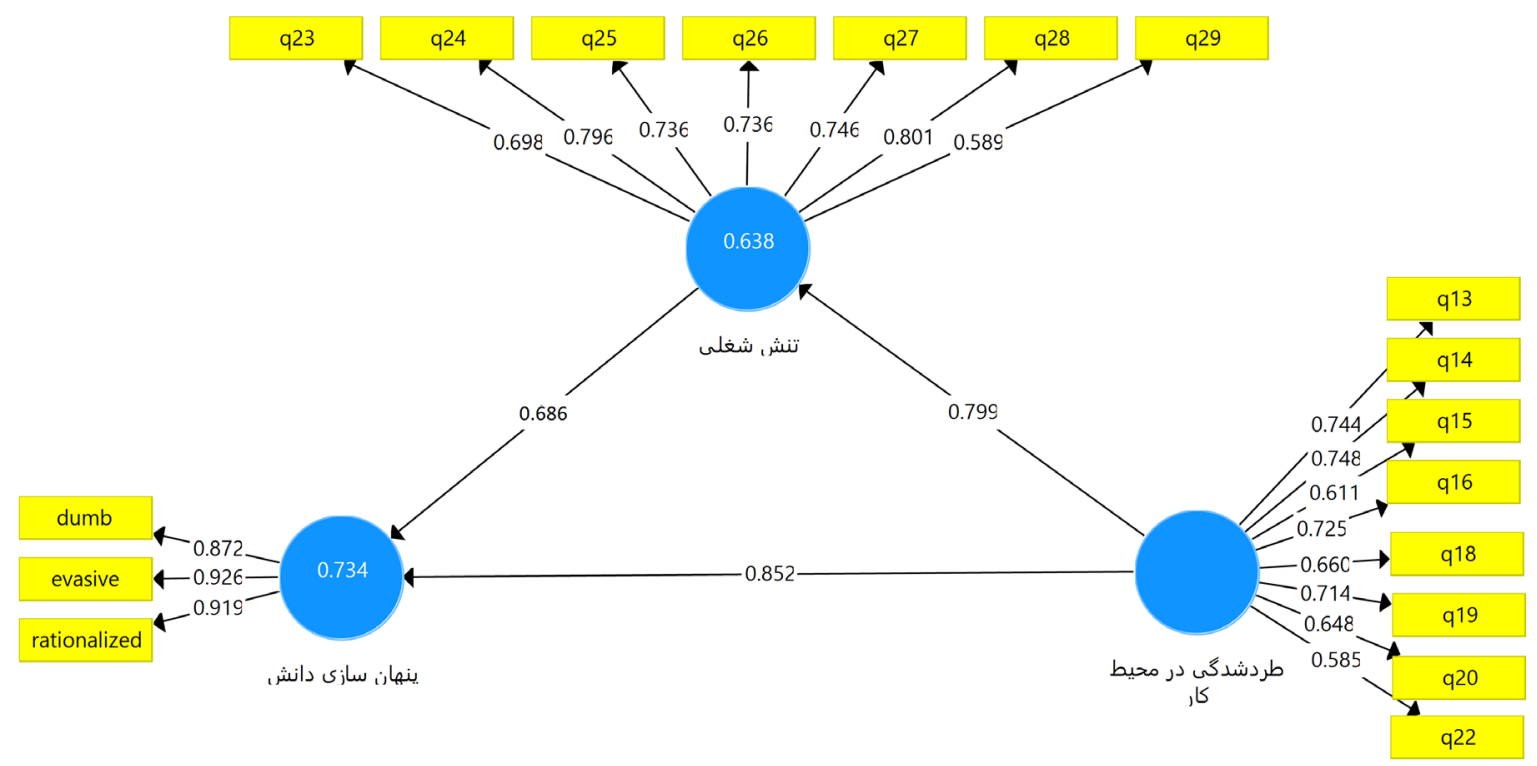

شكل r. مدل آمارهُ تى فرضيههاى يزوهش

جدول 9. نتايج آزمون فرضيهها

\begin{tabular}{|c|c|c|c|}
\hline نتيجه & آمارئ تى & ضريب مسير & رابطه \\
\hline تأييد & rQ/৭TQ & $\cdot / \vee 99$ & طردشدكى در محيط كار بر تنش شغلى تأثير مى كذارد. \\
\hline تأييد & $1 \cdot \mid \wedge M_{1}$ & $\cdot \operatorname{lN} \Delta \mathrm{T}$ & طردشدگى در محيط كار بر ينهانسازى دانش تأثير مى حذارد. \\
\hline تأييد & N/GYF & $\cdot 1919$ & تنش شغلى بر هنهانسازى دانش تأثير مى \\
\hline تأييد & $\Delta / q \cdot r$ & $\cdot / D F \Lambda$ & طردشدكى در محيط كار ازطريق تنش شغلى بر هنهانسازى دانش تأثير مى كذارد. \\
\hline
\end{tabular}

مىشود، درمقايسهبا كذشته اهميت بيشترى به خود گرفته است

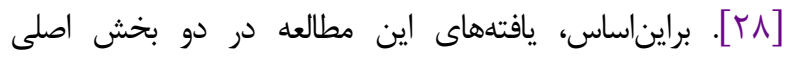
سازماندهى شده است: ا. بررسى اثركذارى طردشدگى در محيط ليط

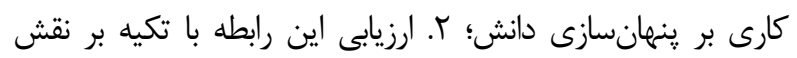
ميانجى تنش شغلى. نتايج اين مطالعه نشان مىدهد كه طردشدگى در محيط كار اثر

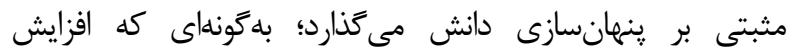

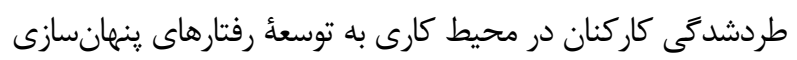
دانش منجر مىشود. اين نوع بدرفتارى در محيطهاى كارى بر شاخصهاى عملكردى فردى و سازمانى تأثير منفى مى مَذارد. طردشدن بلوسيلة همكاران سبب مىشود ارتباط حسى و عاطفى در

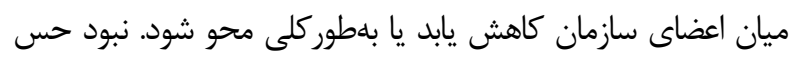
يكدلى در ميان افراد موجب مىشود اعتماد نيز كمرنگ شود؛ بنابراين، بلهاى اينكه روحئُ كار گروهى براى تحقق اهداف سازمان شكل گيرد،
يزوهش حاضر تأثير طردشدگى در محيط كار را بر رفتارهاى ينهانسازى دانش افراد بررسى كرده است. نتايج اين مطالعه توانسته

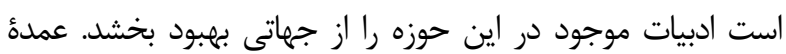
مطالعات ييشين كه از مدلهاى مشابه با يزوهش حاضر استفاده كردهاند، در محيطهاى جدا از بخش درمانى بهكار رفتهاند. اين مطالعه با تأكيد بر حوزه درمان سعى مى كند كه كاربردهاى ناشى از ارزيابى دانى مدل را در اين بخش بلنمايش كذارد. اين مطالعه نشان داد كه بخش مانى

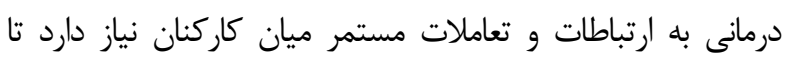

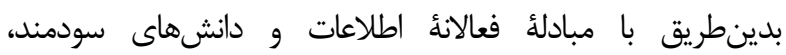
خدماترسانى به جامعهُ كارى خود كسترش يابد. ابتدا بايد كفت ازآنجاكه دانش ادارايى فكرى" است واست و سازمان نمىتواند كاركنانش را به انجام فعاليتهاى انتقال دانش وادار كند، اراده و خواست افراد در اين زمينه بسيار مهمم است [YV] عوامل و زمينههاى فردى كه باعث تقويت رفتارهاى ينهان كردن دانش 
تفاوت نتايج اين مطالعه با يافتههاى تحقيقات مشابه بيشين ابتدا در

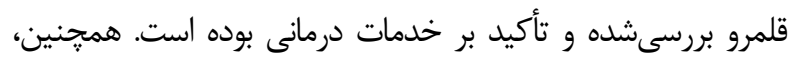

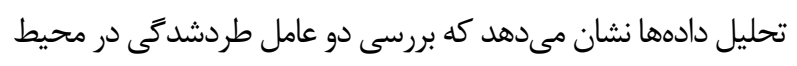

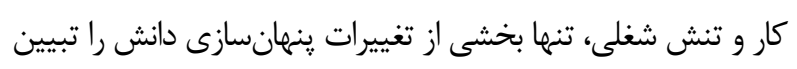

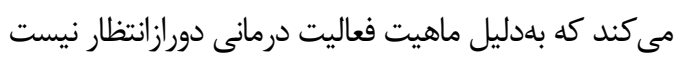

\section{نتيجه}

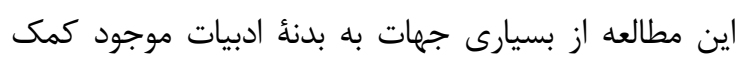

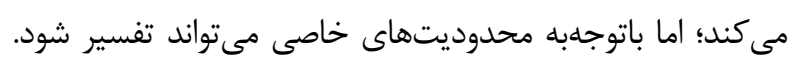

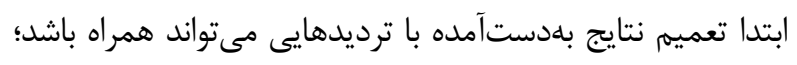

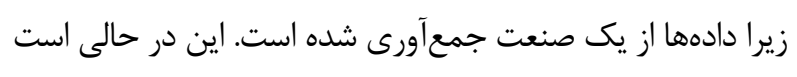

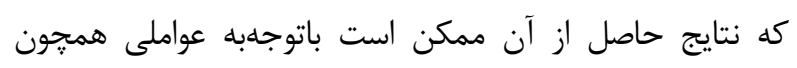

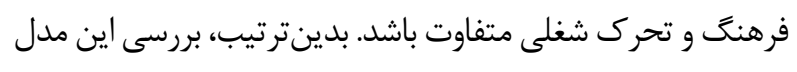

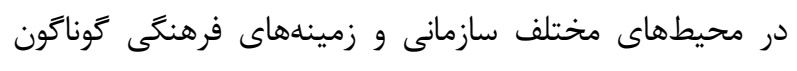

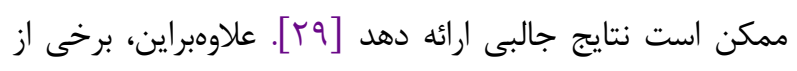

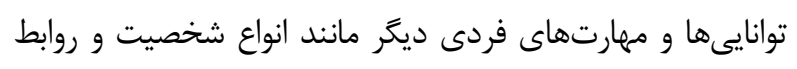

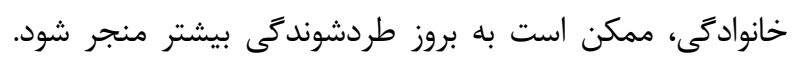

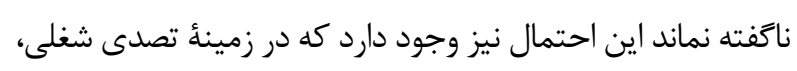

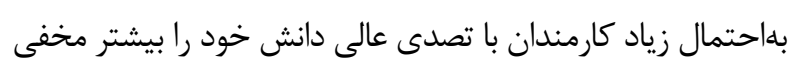
كنند. ازاينرو براى تحقيقات آينده، طراحى طولى بلى بارئ با اطلاعات

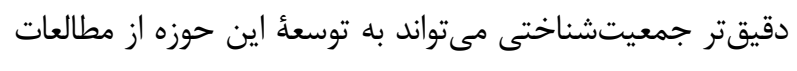
كمكهاى شايانى كند.

\section{تقدير و تشكر}

بدينوسيله نويسندكان مقاله از تمام عوامل و كاركنان

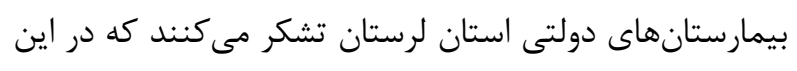
مطالعه مشار كت كردهاند.

\section{تعارض منافع}

بين نويسندكان هيجَّونه تعارضى در منافع وجود ندارد.

\section{سهم نويسندكًان}

اين مقاله با مشاركت نويسندكان تدوين شده و سهمه هر نويسنده از كل مراحل انجام كار • لهدرصد بوده است.

\section{منابع مالى}

منابع مالى موردنياز براى انجام يزوهش حاضر رانى نويسندكان

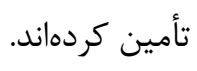

بلنوعى رقابت و تعارض غيرسازنده در ميان اعضاى سازمان ايجاد

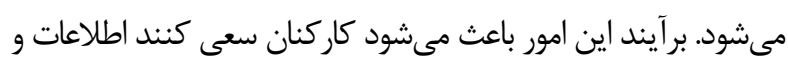

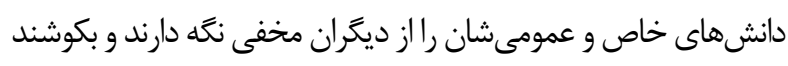

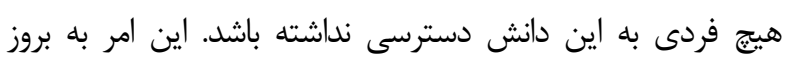

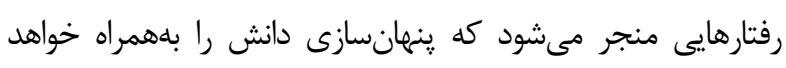

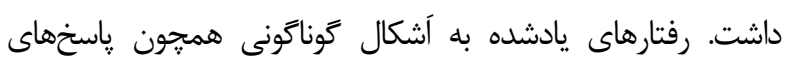

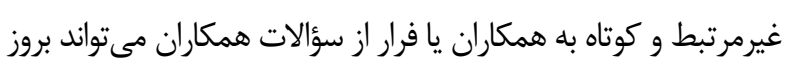

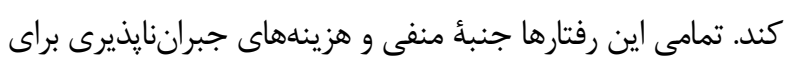

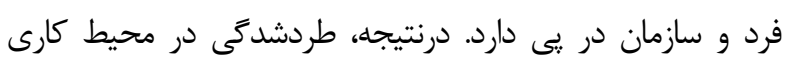

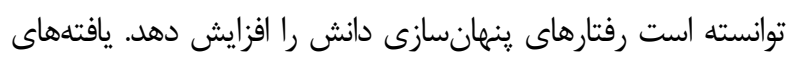

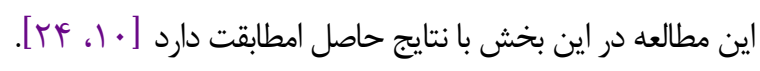

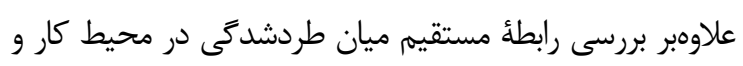

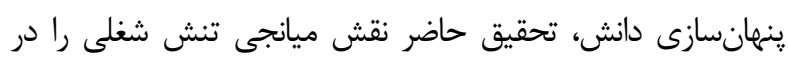

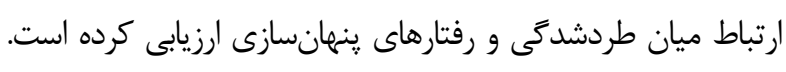

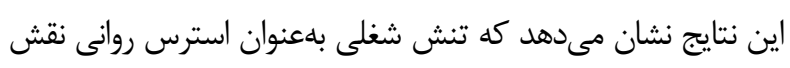

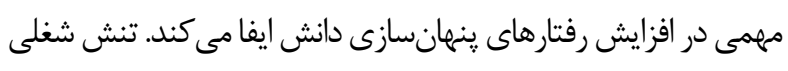

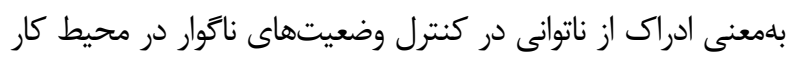

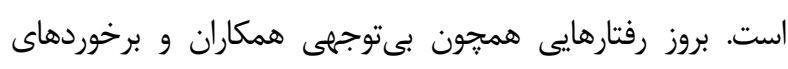

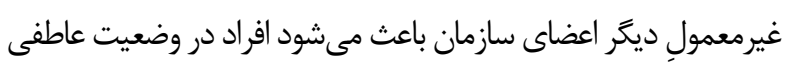

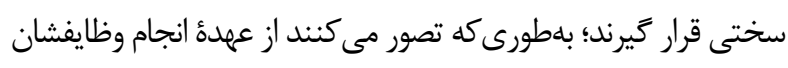

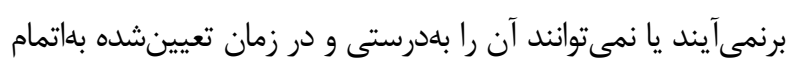

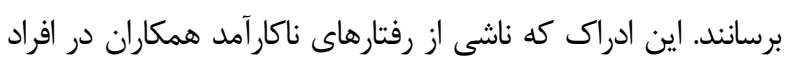

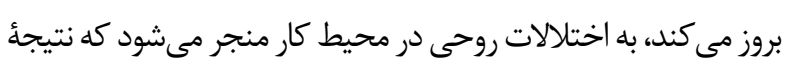

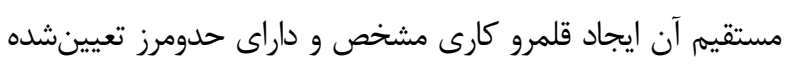

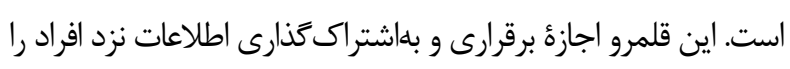

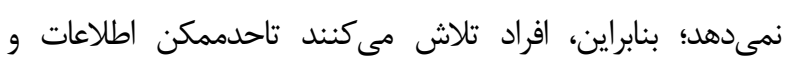

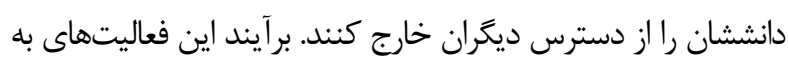

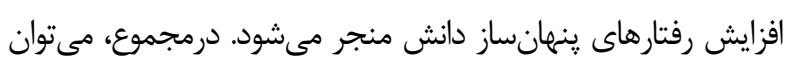

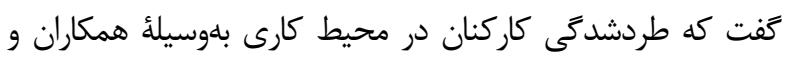

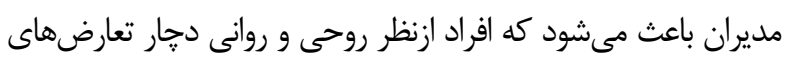

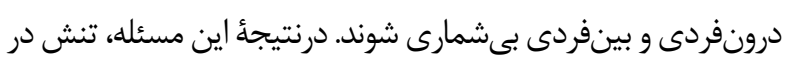

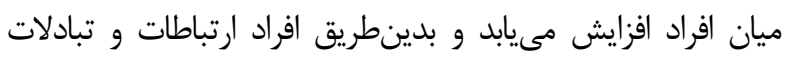

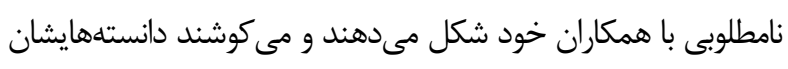

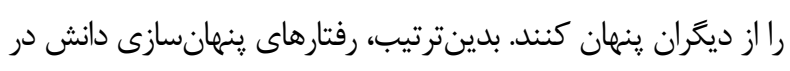

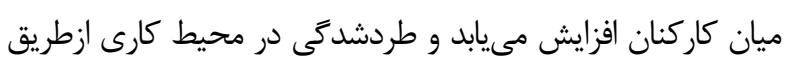

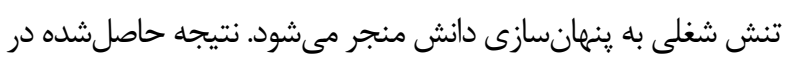

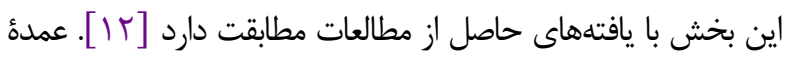




\section{References}

1. Al Qudah NF, Yang Y, Anjum MA. Transformational training programs and quality orientation of employees: does employees' loyalty matter? Sustainability. 2018;10(2):465. [DOI: 10.3390/su10020465]

2. Andersson LM, Pearson CM. Tit for tat? The spiraling effect of incivility in the workplace. Acad Manag Rev. 1999; [DOI:10.5465/amr.1999.2202131]

24(3):452-71.

3. Andreeva T, Kianto A. Does knowledge management really matter? Linking knowledge management practices, competitiveness and economic performance. J Knowl Manag. 2012;16(4): 617-36. [DOI:10.1108/13673271211246185]

4. Azarian Sooshab M, Kashif SM, Behnam M. Presenting a communication model of radical innovation in private clubs of the Iranian Premier Football League through the ability to share and diversify knowledge by examining the mediating role of organizational learning. J Organ Behav Manag Sports Stud. 2019; 6(3):81-96.

5. Balliet D, Ferris DL. Ostracism and prosocial behavior: A social dilemma perspective. Organ Behav Hum Decis Process. 2013;120(2):298-308. [DOI:10.1016/j.obhdp.2012.04.004]

6. Bartol KM, Srivastava A. Encouraging knowledge sharing: The role of organizational reward systems. J Leadersh Organ Stud. 2002;9(1):64-76. [DOI: 10.1177/107179190200900105]

7. Chisholm RF, Kasl SV, Eskenazi B. The nature and predictors of job related tension in a crisis situation: Reactions of nuclear workers to the Three Mile Island accident. Acad Manag J. 1983; 26(3):385-405. [DOI:10.5465/256252]

8. Chung YW. Workplace ostracism and workplace behaviors: A moderated mediation model of perceived stress and psychological empowerment. Anxiety Stress Coping. 2018;31(3):304-17. [DOI:10.1080/10615806.2018.1424835] [PMID]

9. Chung YW, Yang JY. The mediating effects of organization-based self-esteem for the relationship between workplace ostracism and workplace behaviors. Balt J Manag. 2017;12(2):255-70. [DOI:10.1108/BJM-06-2016-0130]

10. Connelly CE, Zweig D. How perpetrators and targets construe knowledge hiding in organizations. Eur $\mathrm{J}$ Work Organ Psychol. 2015;24(3):479-89. [DOI:10.1080/1359432X.2014.931325]

11. Connelly CE, Zweig D, Webster J, Trougakos JP. Knowledge hiding in organizations. J Organ Behav. 2012;33(1):64-88. [DOI:10.1002/job.737]

12. Duffy MK, Ganster DC, Shaw JD, Johnson JL, Pagon $\mathrm{M}$. The social context of undermining behavior at work. Organ Behav Hum Decis Process. 2006;101:105-26.

[DOI:10.1016/j.obhdp.2006.04.005]
13. Eskildsen JK, Nussler ML. The managerial drivers of employee satisfaction and loyalty. Total Qual Manag. 2000;(4-6)11:581-88. [DOI:10.1080/09544120050007913]

14. Ferris DL, Brown DJ, Berry JW, Lian H. The development and validation of the Workplace Ostracism Scale. J Appl Psychol. 2008;93(6):1348366. [DOI:10.1037/a0012743] [PMID]

15. Ferris DL, Lian H, Brown DJ, Morrison R. Ostracism, self-esteem, and job performance: When do we selfverify and when do we self-enhance? Acad Manag J. 2015;58(1):279-97. [DOI:10.5465/amj.2011.0347]

16. Guillon O, Cezanne C. Employee loyalty and organizational performance: A critical survey. J Organ Chang Manag. 2014;27(5):839-50. [DOI:10.1108/JOCM-02-2014-0025]

17. Hales AH, Kassner MP, Williams KD, Graziano WG. Disagreeableness as a cause and consequence of ostracism. Personal Soc Psychol Bull. 2016;42(6):78297. [DOI:10.1177/0146167216643933] [피]

18. Hosseini S, Yousefi B, Bahrami S. Model of the effect of self-esteem on sharing knowledge and noncitizenship behavior with the mediating role of organizational Model (Case study: Sports and Youth departments of Western Provinces). J Organ Behav Manag Sports Stud. 2019;6(3):97-108.

19. House RJ, Rizzo JR. Toward the measurement of organizational practices: Scale development and validation. J Appl Psychol. 1972;56(5):388-96. [DOI: $10.1037 / \mathrm{h} 0033444$ ]

20. Johnson PR, Indvik J. Rudeness at work: Impulse over restraint. Public Pers Manag. 2001;30(4):457-65. [DOI:10.1177/009102600103000403]

21. Lazarus RS. Psychological Stress and the Coping Process. New York, NY: Mc Graw-Hill; 1966.

22. Lim S, Lee A. Work and nonwork outcomes of workplace incivility: Does family support help? J Occup Health Psychol. 2011;16(1):95-111. [DOI:10.1037/a0021726] [PMID]

23. Lin H-F. Linking knowledge management orientation to balanced scorecard outcomes. J Knowl Manag. 2015;19(6):1224-249. [DOI:10.1108/JKM-04-20150132]

24. Lyu Y, Zhu H, Zhong H-J, Hu L. Abusive supervision and customer-oriented organizational citizenship behavior: The roles of hostile attribution bias and work engagement. Int J Hosp Manag. 2016;53:69-80. [DOI:10.1016/j.ijhm.2015.12.001]

25. O'Reilly J, Robinson SL, Berdahl JL, Banki S. Is negative attention better than no attention? The comparative effects of ostracism and harassment at work. Organ Sci. 2014;26(3):774-93. [DOI:10.1287/orsc.2014.0900] 
26. Peng $\mathrm{H}$. Why and when do people hide knowledge? J Knowl Manag. 2013;17(3):398-415. [DOI:10.1108/JKM-12-2012-0380]

27. Ahmad BA, Liu B, Butt AS. Predictors and outcomes of recipients' change proactivity in public organizations of the Kurdistan region of Iraq. Int Public Manag J. 2020;23(6):823-51. [DOI:10.1080/10967494.2019.1588812]

28. Butt AS, Ahmad AB, Shah SHH. Knowledge hiding in a buyer-supplier relationship: A pilot study. Knowl Process Manag. 2020;27(2):1-8. [DOI:10.1002/kpm.1631]

29. Rahimi H. The Effect of Job Nature on Job Adjustment of Nurses in Hospital Affiliated to Kashan University of Medical Sciences. Iran J Ergon. 2020;8(2):17-25. [DOI:10.30699/jergon.8.2.17] 